\title{
PENGARUH PERSEPSI DAN PERILAKU WAJIP PAJAK ATAS PENERAPAN E-FILING TERHADAP KEPATUHAN WAJIP PAJAK PRIBADI YANG TERDAFTAR DI KPP BATAM SELATAN
}

\section{THE EFFECT OF PERCEPTION AND BEHAVIOR OF TAXPAYER FOR APPLICATION E-FILING ON PERSONAL TAX COMPLIANCE COMPLIANCE LISTED IN BATAM SELATAN}

\author{
Mitalina Simanjuntak ${ }^{1}$, Yentina Siregar ${ }^{2}$ \\ ${ }^{1}$ (Prodi Akuntansi, Fakultas Ekonomi, Universita Riau Kepulauan, Indonesia) \\ 2 (Prodi Akuntansi, Fakultas Ekonomi, Universitas Riau Kepulauan, Indonesia) \\ Mitalina48@gmail.com, ${ }^{2}$ yentina.siregari@gmail.com
}

\begin{abstract}
Abstrak
Pelaporan pajak menggunakan system E-Filing adalah terobosan baru yang dilakukan oleh Direktorat Jendral Pajak untuk meningkatkan kualitas pelayanannya bagi para pelapor pajak. Populasi penelitian ini ialah masyarakat yang terdaftar sebagai wajib pajak pribadi di KPP Batam Selatan.Tujuan penelitian ini untuk mengetahui persepsi dan perilaku masyarakat atas penerapan e-filing. Metode yang digunakan dalam penelitian ini adalah metode kuantatif dan teknik pengumpulan data dilakukan dengan menyebar kueisioner ke 100 (seratus) responden. Hasil penelitian ini menunjukkan bahwa persepsi dan perilaku berpengaruh signifikan terhadap kepatuhan wajib pajak yang terdafrat di KPP Batam Selatan. Dimana dari hasil uji $R^{2}$ yang dilakukan, nilai koefisien determinasinyasebesar 0,189 sama dengan 18,9\%. (Dari hasil analisa menggunakan uji $R^{2}$ ), ditemukan bahwa nilai koefisien determinasinya adalah 0,189 sama dengan 18,9\%. Angka tersebut mengandung arti (Menunjukkan) bahwa variable persepsi dan perilaku berpengaruh terhadap kepatuhan sebesar 18,9\%, sedangkan sisanya $(100 \%-18,9 \%=81,1 \%)$ dipengaruhi oleh variabel lain diluar model regresi ini.
\end{abstract}

Kata Kunci: Persepsi penerapan E-filing, Perilaku Wajib Pajak, E-filing, Kepatuhan Wajib Pajak Orang Pribadi

\begin{abstract}
Tax reporting using the E-filling system is a new breakthrough made by Directorate General of Taxes to improve the quality of its services for tax reporters. The population of this research is the people registered as personal taxpayers at KPP Batam Selatan. The purpose of this research was to determine people's perceptions and behavior on the implementation of E-filling system. The method used in this research is a quantitative method and the technique of the data collection is done by distributing questionnaires to 100 (one hundred) respondents. The results of this research indicate that perceptions and behaviors have a significant effect on compliance of taxpayers who registered at KPP Batam Selatan. From the analysis using R2 test, it was found that the coefficient is 0,189 equal to $18,9 \%$. This figure shows that the perception and behavior variables affect to compliance by $18,9 \%$, while the rest $(100 \%-18,9 \%=81,1 \%)$ is influenced by other variables outside the regression model.

Keywords: Perception application of e-filing, Behavior taxpayer, E-filing, Individual Taxpayer Compliance
\end{abstract}

\section{PENDAHULUAN}


Proses pelaporan pajak Direktorat Jenderal Pajak telah melakukan berbagai perubahan mendasar, mulai dari restrukturisasi organisasi dan perubahan sistem kerja Kantor Pelayanan Pajak, sampai dengan pengembangan sumber daya manusia dan penggunaan teknologi informasi dalam administrasi perpajakan. Hal ini merupakan wujud dari modernisasi perpajakan di Indonesia.Penerapan modernisasi perpajakan bertujuan untuk mengoptimalkan pelayanan kepada Wajib Pajak dan transparansi dalam pemungutan pajak sejalan dengan UU No. 28 Tahun 2007 yang memberikan banyak kepastian hukum.

Direktorat Jenderal Pajak mencoba untuk memberikan pelayanan yang prima kepada para Wajib Pajak dan melakukan inovasi-inovasi dalam pelayanannya.Salah satu inovasi yang dilakukan oleh Direktorat Jenderal Pajak adalah dengan melakukan perubahan pada administrasi pelaporan perpajakan.Direktorat Jenderal Pajak membuat sebuah sistem yang lebih sederhana dalam pelaporan pajak dengan e-filing.Adanya sistem pelaporan pajak dengan menggunakan e-filing dapat memudahkan Wajib Pajak. Wajib Pajak dapat melaporkan SPTnya 24 jam selama 7 hari. Hal ini berarti wajib pajak dapat melaporkan SPTnya meskipun pada hari libur.Sistem ini sangat bermanfaat untuk wajib pajak yang tidak melapokan SPTnya dengan alasan sibuk.Selain itu, dengan adanya $e$ filing ini dapat mengurangi biaya yang ditimbulkan dari penggunaan kertas.

Namun, faktanya dalam proses pelaporan pajak, masih ada wajib pajak yang kebingungan untuk melaporkan pajak menggunakan e-filing seharusnya Wajib Pajak sudah mengerti tata cara pelaporan pajak menggunakan E-filing mengingat E-filing telah resmi beroperasi selama 3 tahun ( 2015 - 2018 ). Bukan hanya itu saja KPP Batam Selatan berpendapat bahwa Wajib Pajak sering mengalami kesulitan ketika akan masuk ke sistem administrasi elektronik (esystem) atau mengirimkan laporan pajaknya, sehingga Wajib Pajak harus menyampaikan secara manual ke KPP Batam Selatan. Masalah lainnya adalah Wajib Pajak sudah membayar pajak, tetapi masih timbul kebingungan pada Wajib Pajak dalam memenuhi kewajiban perpajakannya, yaitu Wajib Pajak sering tidak menyampaikan SPT tepat waktu, SPT yang di sampaikan pun tidak semuanya sesuai dengan kebenaran. Terkadang SPT yang disampaikan wajib pajak tidak sesuai dengan kenyataannya (tidak akurat).

Ada juga Wajib Pajak yang belum mengerti sepenuhnya cara melaporkan SPTnya secara elektronik, kerap kali setiap hendak melaporkan SPT Wajib Pajak meminta Wajib Pajak lain untuk membantu atau bahkan menggantikan melaporkan pajak yang seharusnya dilakukan Wajib Pajak itu sendiri. Padahal banyak manfaat yang didapatkan apabila menggunakan e-filing ini. Dari latar belakang masalah di atas maka peneliti tertarik untuk melakukan penelitian dengan judul"Pengaruh Persepsi dan Perilaku Wajib Pajak atas Penerapan E-Filing Terhadap Kepatuhan Wajib Pajak Pribadi yang Terdafatar di KPP Batam Selatan. 


\section{Landasan Teori}

Persepsi adalah suatu proses dengan cara apa seseorang melakukan pemilihan, penerimaan, pengorganisasian, dan penginterpretasian atas informasi yang diterimanya dari lingkungan (Herlan dan Yono 2013)". "Persepsi adalah proses dimana individu mengatur dan menginterpretasikan kesankesan sensoris mereka guna memberikan arti bagi lingkungan mereka (Robbins 2008).

Berdasarkan teori di atas dapat disimpulakan bahwa persepi wajip pajak adalah proses seseorang dalam memilih, menerima, menginterpresentasikan suatu informasi tentang ketentuan umum dan tata cara perpajakan yang di atur oleh UUD No.16 Tahun 2019. Seorang wajip pajak mampu memilah suatu informasi yang di peroleh dari kantor pelayan pajak kemudian memahami dan menilai informasi tersebut.

Menurut Rahayu (2010) Menyatakan bahwa perilaku wajib pajak adalah karakteristik wajib pajak yang dicerminkan oleh budaya, sosial dan ekonomi yang tergambar dalam tingkat kesadaran mereka dalam membayar pajak.

Menurut Manurung (2009) indikator perilaku wajib pajak terdiri dari:

1. Tingkat kerumitan suatu peraturan

2. Kurangnya sosialisasi peraturan Berat atau ringannya sanksi perpajakan

3. Moral masyarakat

Beberapa ahli membedakan bentuk-bentuk perilaku ke dalam tiga domain yaitu pengetahuan, sikap, dan tindakan atau sering kita dengar dengan istilahpengetahuan, sikap, latihaan (Sarwono, 2004).

Kepatuhan Wajib Pajak dapat diartikan sebagai keadaan dimana Wajib Pajak memenuhi semua kewajiban perpajakan dan melaksanakan hak perpajakannya. Siti Kurnia Rahayu (2010) memiliki pendapat bahwa Kepatuhan memenuhi kewajibhan perpajakan secara sukarela merupakan tulang pungggung sistem pelaporan pajak secara online, dimana Wajib Pajak bertanggung jawab menetapkan sendiri kewajiban perpajakan dan kemudian secara akurat dan tepat waktu membayar dan melaporkan pajaknya tersebut.

\section{Metode Penelitian}

Penelitian ini dilakukan pada KPP Batam Selatan Di Jl Adhya Building Tower Blok A 1 Komplek Permata Niaga Bukit Indah, Sukajadi, Batam Kota, Kota Batam, Kepulauan Riau 29444 dimana para pekerja yang bekerja di pusat industry batam atau yang sering disebut dengan Muka Kuning Batam terdaftar sebagai Wajib Pajak Orang Pribadi. dan sesuai dengan ketentuan Peraturan Menteri Keuangan No.9/PMK.03/2018 mulai tanggal 1 April 2018, SPT Masa PPh 21 wajib dilaporkan secara online (E-Filing).

Jumlah sample dalam penelitian ini sebanyak 100 sample karena menurut Suharsimi Arikunto ( 2010 ) sampel adalah sebahagian atau wakil dari populasi yang akan di teliti, jika populasinya kurang dari 100 sebaiknya jumlah populasi tersebut dijadikan sebagai jumlah sampel dan jika jumlah populasinya besar maka 100 sample atau lebih dikatakan cukup untuk mewakili jumlah populasi 
tersebut. Untuk memperoleh data dan informasi serta keterangan-keterangan bagi kepentingan penulis, maka dalam penelitian ini penulis menggunakan beberapa teknik pengumpulan data, yaitu: kueisioner dengan cara memberikan pertayaan atau peryataan tertulis kepada responden.

\section{Hasil Penelitian dan Pembahasan}

Penelitian ini dilakukan terhadap wajib pajak yang terdaftar di KPP Batam Selatan. Peneliti menyebar kuesioner pada responden yang bekerja di PT NOK Asia Batam dan beberapa masyarakat yang melaporkan pajak di KPP Pratama Batam Selatan dan total kuesioner yang di sebar sebanyak 100 Wajib Pajak. Penyebaran kuesioner dilakukan pada tanggal 8 - 30 April 2019. Dalam proses penyebaran kueisioner peneliti mencoba untuk tidak focus kepada satu lokasi ataupun instansi yang WPnya melapor pajak di KPP Pratama Batam selatan. Hal ini dilakukan peneliti untuk mendapatkan hasil yang lebih baik daripada harus focus menyebar kuesioner $\mathrm{d}$ satu lokasi atau instansi tertentu.

\section{Pengujian Validitas}

\section{a. Hasil Uji Validitas Variabel Persepsi (XI)}

Berdasarkan hasil uji validitas dapat diketahui bahwa semua pernyataan variabel persepsi dinyatakan valid, karena nilai $r$ hitung untuk semua variabel memiliki nilai yang lebih besar dari $r$ tabel $(0,1966)$.

Tabel 1

Hasil Uji Validitas Persepsi

\begin{tabular}{|c|c|c|c|}
\hline Pertanyaan & R hitung & R table & Keterangan \\
\hline 1 & 0,472 & 0,1966 & Valid \\
\hline 2 & 0,761 & 0,1966 & Valid \\
\hline 3 & 0,795 & 0,1966 & Valid \\
\hline 4 & 0,735 & 0,1966 & Valid \\
\hline 5 & 0,472 & 0,1966 & Valid \\
\hline 6 & 0,761 & 0,1966 & Valid \\
\hline 7 & 0,795 & 0,1966 & Valid \\
\hline 8 & 0,735 & 0,1966 & Valid \\
\hline
\end{tabular}

Sumber : Data Primer yang diolah, 2019

Dari hasil uji validitas pada variabel persepsi terlihat bahwa semua item skor dari setiap pernyataan adalah Pearson Correlation $\geq \mathrm{r}$ tabel, hal ini menjelaskan bahwa r-hitung $\geq \mathrm{r}$-tabel yang berarti bahwa setiap instrumen dari item pernyataan dinyatakan valid. Dengan demikian maka item pernyataan dari variabel Persepsi $\left(\mathrm{X}_{1}\right)$ dinyatakan valid dan dapat digunakan dalam pengujian selanjutnya.

\section{b. Uji Validitas Perilaku}


Berdasarkan hasil uji validatss dapat diketahui bahwa semua pertanyaan variable perilaku dinyatakan valid, karena nilai $\mathrm{r}$ hitung untuk semua variabel memiliki nilai yang lebih besar dari $\mathrm{r}$ tabel (0.1966).

Tabel 2

Hasil Uji Validitas Perilaku

\begin{tabular}{|c|c|c|c|}
\hline Pernyataan & R hitung & R table & Keterangan \\
\hline 1 & 0,473 & 0.1966 & Valid \\
\hline 2 & 0,698 & 0.1966 & Valid \\
\hline 3 & 0,724 & 0.1966 & Valid \\
\hline 4 & 0,715 & 0.1966 & Valid \\
\hline 5 & 0,751 & 0.1966 & Valid \\
\hline 6 & 0,269 & 0.1966 & Valid \\
\hline 7 & 0,321 & 0.1966 & Valid \\
\hline
\end{tabular}

Sumber : Data Primer yang diolah, 2019

Dari hasil uji validitas pada variabel perilaku terlihat bahwa semua item skor dari setiap pernyataan adalah Pearson Correlation $\geq \mathrm{r}$ tabel, hal ini menjelaskan bahwa r-hitung $\geq \mathrm{r}$-tabel yang berarti bahwa setiap instrumen dari item pernyataan dinyatakan valid. Dengan demikian maka item pernyataan dari variabel perilaku $\left(\mathrm{X}_{2}\right)$ dinyatakan valid dan dapat digunakan dalam pengujian selanjutnya.

\section{c. Uji Validitas Kepatuhan}

Berdasarkan hasil uji validatss kepatuhan dapat diketahui bahwa semua pertanyaan variable Kepatuhan dinyatakan valid, karena nilai $\mathrm{r}$ hitung untuk semua variabel memiliki nilai yang lebih besar dari $r$ tabel $(0.1966)$.

Tabel 3

Hasil Uji Validitas Kepatuhan

\begin{tabular}{|c|c|c|c|}
\hline Pernyataan & R hitung & R table & Keterangan \\
\hline 1 & 0,423 & 0.1966 & Valid \\
\hline 2 & 0,381 & 0.1966 & Valid \\
\hline 3 & 0,661 & 0.1966 & Valid \\
\hline 4 & 0,705 & 0.1966 & Valid \\
\hline 5 & 0,730 & 0.1966 & Valid \\
\hline 6 & 0,805 & 0.1966 & Valid \\
\hline
\end{tabular}

Sumber : Data Primer yang diolah, 2019

Dari hasil uji validitas pada variabel Kepatuhan terlihat bahwa semua item skor dari setiap pernyataan adalah Pearson Correlation $\geq \mathrm{r}$ tabel, hal ini menjelaskan bahwa r-hitung $\geq \mathrm{r}$-tabel yang berarti bahwa setiap instrumen dari item pernyataan dinyatakan valid. Dengan demikian maka item 
pernyataan dari variabel Minat $\left(\mathrm{X}_{1}\right)$ dinyatakan valid dan dapat digunakan dalam pengujian selanjutnya.

\section{Uji Reabilitas}

Uji Reabilitas digunakan untuk mengetahui tingkat reliable alat ukirr dengan menghitung korrelasi cronbach alpha dengan masing-masing butir pertanyaan dalam satu variabel. Dengan ketentuan $\alpha>0,6$ dinyatakan reliable dan $\alpha<0,6$ dinyatakan tidak reliable (Ghozali : 2005)

Tabel 4

Hasil Uji Reabilitas

\begin{tabular}{|c|c|c|c|}
\hline Variabel & Item & $\begin{array}{c}\text { Koefisien } \\
\text { Cronbach's Alpha } \\
(\boldsymbol{\alpha})\end{array}$ & Keterangan \\
\hline Persepsi & 8 & 0,84 & Realibel \\
\hline Perilaku & 7 & 0,68 & Realibel \\
\hline Kepatuhan & 6 & 0,70 & Realibel \\
\hline
\end{tabular}

Sumber: Data Primer yang diolah, 2019

Hasil uji reliabilitas tersebut menunjukkan bahwa semua variabel mempunyai koefisien Alpha yang cukup besar diatas 0,6 sehingga dapat dikatakan semua konsep pengukur masing-masing variabel dari kuesioner adalah reliable sehingga untuk selanjutnya item-item pada masing-masing konsep variabel tersebut layak digunakan sebagai alat ukur.

\section{Uji Asumsi Klasik}

\section{a. Uji Normalitas}

Teknik yang digunakan untuk menguji normalitas adalah Kolmogorov-Smirnov.Hasil dari uji normalitas melalui perhitungan menggunakan software SPSS versi 20.

\section{Tabel 5}

\section{Hasil Uji Normalitas}

\begin{tabular}{|c|c|c|c|}
\hline \multirow{2}{*}{} & \multicolumn{3}{|c|}{ Kolmogorov-Smirnov $^{\mathrm{a}}$} \\
\cline { 2 - 4 } & Statistic & Df & Sig. \\
\hline Persepsi & .077 & 100 & .156 \\
\hline Perilaku & .075 & 100 & .185 \\
\hline Kepatuhan & .081 & 100 & .108 \\
\hline
\end{tabular}

Sumber: Data Primer yang diolah, 2019

Tabel 5 menyatakan bahwa data telah berdistribusi dengan normal karena nilai signifikan lebih dari 0,05. Data tersebut dapat disusun uji normalitas data sebagai berikut :

\section{Pengujian data Persepsi}

Pada data persepsi signifikansi 0,156 dapat disimpulkan bahwa data persepsi terdistribusi normal. 
2. Pengujian data Perilaku

Pada data perilaku signifikansi 0,185 dapat disimpulkan bahwa data minat terdistribusi normal.

3. Pengujian data kepatuhan

Pada data kepatuhan signifikansi 0,108 dapat disimpulkan bahwa data minat terdistribusi normal.

\section{b. Uji Multikolinearitas}

Uji multikolinearitas bertujuan untuk menguji apakah model regresi yang digunakan ditemukan adanya variabel-variabel bebas (independent) berkolerasi satu sama lain. Model regresi yang baik sebaiknya tidak terjadi masalah multikolinearitas.Untuk melihat ada tidaknya multikolinearitas di dalam model regresi adalah dengan melihat nilai tolerance dan lawannya serta nilai Variance Inflation Factor (VIF).

Tabel 6

Hasil Uji Multikolinearitas

\begin{tabular}{|c|c|c|c|c|c|c|c|c|}
\hline \multirow{2}{*}{\multicolumn{2}{|c|}{ Model }} & \multicolumn{2}{|c|}{$\begin{array}{l}\text { Unstandardize } \\
\text { d Coefficients }\end{array}$} & \multirow{2}{*}{$\begin{array}{c}\text { Standardi } \\
\text { zed } \\
\text { Coefficie } \\
\text { nts } \\
\text { Beta }\end{array}$} & \multirow[b]{2}{*}{$\mathrm{T}$} & \multirow[b]{2}{*}{ Sig. } & \multicolumn{2}{|c|}{ Collinearity Statistics } \\
\hline & & B & $\begin{array}{l}\text { Std. } \\
\text { Error }\end{array}$ & & & & Tolerance & VIF \\
\hline \multirow[t]{3}{*}{1} & (Constant) & 8.374 & 2.785 & & 3.007 & .003 & & \\
\hline & Persepsi & .157 & .060 & .240 & 2.617 & .010 & .996 & 1.004 \\
\hline & Perilaku & .330 & .080 & .378 & 4.125 & .000 & .996 & 1.004 \\
\hline
\end{tabular}

Sumber : Data Primer yang diolah, 2019

Variabel yang menyebabkan multikolinearitas dapat dilihat dari nilai toleransi yang lebih kecil dari 0,1 atau VIF yang lebih besar dari nilai 10.Dari output regresi didapatkan nilai toleransi lebih besar dari 0,1 yaitu 1,004 dan nilai VIF lebih kecil dari 10 yaitu 1,004 sehingga tidak terjadi multikolinearitas ini berarti hasil data regresi yang baik.

\section{c. Uji Heteroskedastisitas}

\section{Gambar 1}

\section{Hasil Uji Heteroskedasitas}

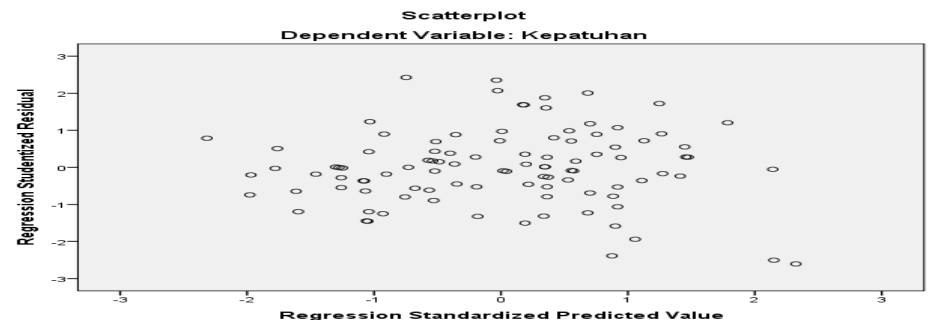

Sumber : Hasil Olahan SPSS20, 2019 
Uji Heteroskedastisitas digunakan untuk mengetahui ada atau tidaknya ketidaksamaan varian dari residual pada model regresi. Dari output regresi titik-titik tidak membentuk pola yang jelas dan titik-titik menyebar diatas dan dibawah angka 0 pada sumbu $\mathrm{Y}$, berarti tidak terjadi heteroskedastisitas dalam model regresinya.

\section{Uji Hipotesis}

\section{a. Hasil Uji t}

Uji t digunakan untuk menguji hubungan antara masing-masing variabel bebas terhadap variabel terikat secara parsial atau per variabel. Setelah menetukan formula hipotesis, maka tingkat signifikasi yang dipakai adalah 0,05 . Pada output Coefficien menjelaskan tentang uji t yaitu uji secara parsial, sedangkan signifikansi mengukur tingkat signifikasi dari uji t, ukurannya jika signifikansi kurang dari 0,05 maka ada pengaruh secara persial antara variabel independen terhadap variabel dependen.

Tabel 7

Hasil Uji t Variabel X1

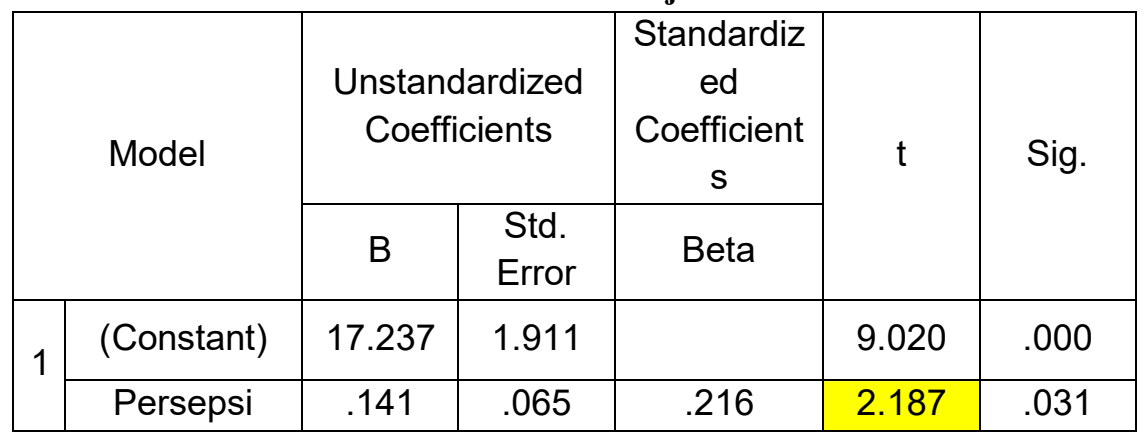

Sumber : Data Primer yang diolah, 2019

Berdasarkan uji statistik pada tabel 4.13 di atas menunjukkan bahwa pengaruh persepsi (X1)terhadap kepatuhan menunjukkan nilai signifikan sebesar 0,031 yang lebih kecil dari taraf signifikan yang digunakan $0,031<0,05$, sehingga dapat dikatakan $\mathrm{H}_{\mathrm{a}}$ diterima.Dari hasil $\mathrm{t}$ hitung di dapat nilai sebesar 2,187 dan di bandingkan dengan t tabel sebesar 1,660715 sehingga 2,187> $1,660715$ ( $\mathrm{t}$ hitung $>\mathrm{t}$ tabel $)$.

Jadi dapat disimpulkan bahwa variabel persepsi memiliki pengaruh yang signifikan terhadap minat dengan sig $(0,031<0,05)$ dan $\mathrm{t}$ hitung $>\mathrm{t}$ tabel $(2,187>1,660715)$. 
Tabel 8

Hasil Uji t Variabel X2

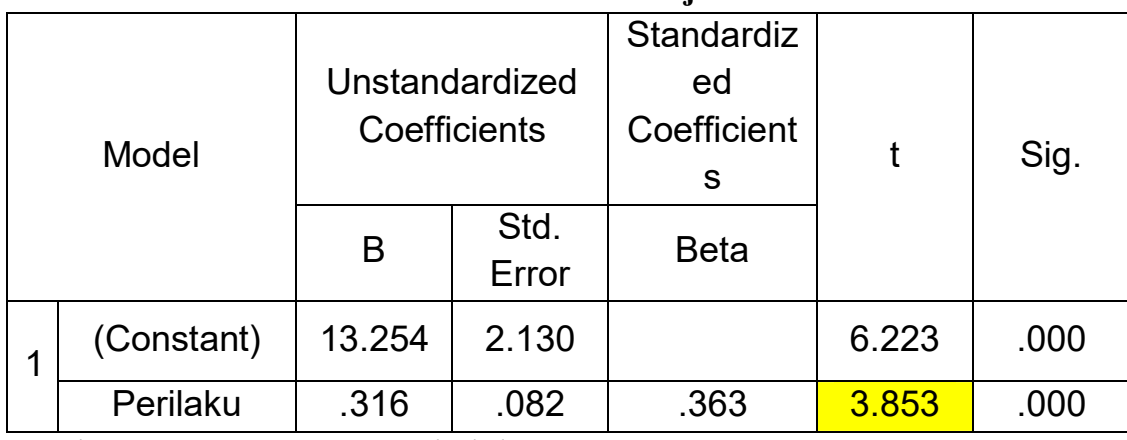

Sumber : Data Primer yang diolah, 2019

Berdasarkan uji statistik pada Tabel 8 di atas menunjukkan bahwa pengaruh perilaku (X2)terhadap kepatuhan menunjukkan nilai signifikan sebesar 0,000 yang lebih kecil dari taraf signifikan yang digunakan $0,000<0,05$, sehingga dapat dikatakan $\mathrm{H}_{\mathrm{a}}$ diterima.Dari hasil $\mathrm{t}$ hitung di dapat nilai sebesar 3,853 dan di bandingkan dengan t tabel sebesar 1,660715 sehingga 3,853> 1,660715 ( $\mathrm{t}$ hitung $>\mathrm{t}$ tabel ).

Jadi dapat disimpulkan bahwa variabel persepsi memiliki pengaruh yang signifikan terhadap minat dengan $\operatorname{sig}(0,000<0,05)$ dan $t$ hitung $>t$ tabel $(3,853>1,660715)$.

\section{b. Uji F}

Uji F dilakukan untuk membuktikan apakah terdapat pengaruh variabel X terhadap variabel Y secara simultan. Apabila nilai signifikan $<0,05$ maka secara simultan berpengaruh signifikan, sebaliknya jika nilai signifikan $>0,05$ maka secara simultan tidak berpengaruh signifikan. Berikut hasil uji $\mathrm{F}$ untuk variabel citra merek, harga, dan kepercayaan terhadap minat beli.

Tabel 9

Hasil Uji f

\begin{tabular}{|c|c|c|c|c|c|c|}
\hline \multicolumn{2}{|c|}{ Model } & $\begin{array}{c}\text { Sum of } \\
\text { Square } \\
\text { s }\end{array}$ & Df & $\begin{array}{l}\text { Mean } \\
\text { Square }\end{array}$ & $F$ & Sig. \\
\hline \multirow[t]{3}{*}{1} & $\begin{array}{l}\text { Regressio } \\
n\end{array}$ & $\begin{array}{r}323.94 \\
8\end{array}$ & 2 & $\begin{array}{r}161.97 \\
4\end{array}$ & $\begin{array}{r}11.28 \\
9\end{array}$ &, $000^{6}$ \\
\hline & Residual & $\begin{array}{r}1391.8 \\
12\end{array}$ & 97 & 14.349 & & \\
\hline & Total & $\begin{array}{r}1715.7 \\
60\end{array}$ & 99 & & & \\
\hline
\end{tabular}

Sumber: Data Primer yang diolah, 2019

Berdasarkan Tabel 9 di atas dapat dilihat bahwa nilai $\mathrm{F}$ untuk hasil uji regresi menunjukkan nilai 11.289, dimana nilai $F_{\text {hitung }}>F_{\text {tabel }},(11.289>3,09117)$. Begitu juga dengan nilai Sig yang bernilai $0,000<0,05$. Hal ini menunjukkan bahwa variabel persepsi dan perilaku berpengaruh signifikan terhadap kepatuhan wajib pajak pribadi. 


\section{c. Uji Regresi Linear Berganda}

Tabel 10

Hasil Uji Regresi Linear Berganda

\begin{tabular}{|c|c|c|c|c|}
\hline & & \multicolumn{2}{|c|}{$\begin{array}{c}\text { Unstandardized } \\
\text { Coefficients }\end{array}$} & $\begin{array}{c}\text { Standardized } \\
\text { Coefficients }\end{array}$ \\
\hline \multicolumn{2}{|c|}{ Model } & B & Std. Error & Beta \\
\hline \multirow[t]{3}{*}{1} & (Constant) & 8.374 & 2.785 & \\
\hline & X1 & .157 & .060 & .240 \\
\hline & $\mathrm{X} 2$ & .330 & .080 & .378 \\
\hline
\end{tabular}

Sumber : Data Primer yang diolah, 2019

Berdasarkan tabel di atas suatu analisis model regresi linear berganda adalah $\mathrm{Y}=8,374+0,157 \mathrm{X} 1+$ $0,330 \mathrm{X}_{2}+0,080$. Dari Persamaan tersebut dapat dijelaskan bahwa :

1. Konstanta (a)

Persepsi, jika tanpa ada $\left(\mathrm{X}_{1}=0\right)$, maka nilai minat sebesar 8,374.

2. Persepsi $\left(\mathrm{X}_{1}\right)$ terhadap $\mathrm{Y}$

Nilai persepsi untuk $\mathrm{X}_{1}$ sebesar 0,157 yang mana menunjukkan setiap kenaikan persepsi satusatuan, maka variabel $\mathrm{Y}$ akan naik 0,157 dengan asumsi bahwa variabel bebas yang lain dari model regresi adalah konstan.

3. Perilaku $\left(\mathrm{X}_{2}\right)$ terhadap $\mathrm{Y}$

Nilai perilaku untuk $\mathrm{X}_{2}$ sebesar 0,330 yang mana menunjukkan setiap kenaikan persepsi satusatuan, maka variabel $\mathrm{Y}$ akan naik 0,330 dengan asumsi bahwa variabel bebas yang lain dari model regresi adalah konstan

\section{d. Hasil Uji Determinasi $\left(R^{2}\right)$}

Tabel 11

Hasil Uji Determinasi

\begin{tabular}{|l|l|r|r|r|}
\hline Model & $\mathrm{R}$ & $\begin{array}{c}\mathrm{R} \\
\text { Square }\end{array}$ & $\begin{array}{c}\text { Adjusted } \\
\mathrm{R} \\
\text { Square }\end{array}$ & $\begin{array}{c}\text { Std. } \\
\text { Error of } \\
\text { the } \\
\text { Estimate }\end{array}$ \\
\hline 1 &, $435^{\mathrm{a}}$ & .189 & .172 & 3.788 \\
\hline
\end{tabular}

Sumber : Data Primer yang diolah, 2019

Dari hasil diatas diketahui nilai koefisien determinasi (R square) sebesar 0,189 ( nilai 0,189 adalah pengkuadratan dari koefisien atau $\mathrm{R}$, yaitu $0,435 \times 0,435=0,189$ ). Besarnya angka koefisien determinasi (R Square) 0,189 sama dengan 18,9\%. Angka tersebut mengandung arti bahwa variable 
persepsi dan perilaku berpengaruh terhadap kepatuhan sebesar $18,9 \%$, sedangkan sisanya $(100 \%$ $18,9 \%=81,1 \%$ ) dipengaruhi oleh variabel lain diluar model regresi ini.

\section{Kesimpulan dan Saran}

Penelitian bertujuan untuk mengetahui seberapa besar pengaruh VariabelPersepsi dan Variabel Perilaku terhadap kepatuhan wajib pajak pribadi secara parsial ataupun simultan. Berikut beberapa kesimpulan dalam penelitian ini:

1. Terdapat pengaruh yang signifikan antara Persepsi Wajib Pajak atas penerapan e-filing terhadap kepatuhan pajak orang pribadi yang terdaftar di KPP Batam Selatan. H1 Diterima

2. Terdapat pengaruh yang signifikan antara Perilaku wajib pajak atas penerapan E-Filing terhadap kepatuhan wajib pajak orang pribadi yang terdaftar di KPP BatamSelata. H2 Diterima

3. Terdapat pengaruh yang signifikan antara Persepsi dan Perilaku Wajib Pajak terhadap kepatuhan wajib pajak orang pribadi yang terdaftar di KPP Batam Selatan. H3 Diterima. Hasil uji koefisien determinasi (R Square) memperoleh hasil 0,189 sama dengan 18,9\%. Angka tersebut mengandung arti bahwa variable persepsi dan perilaku berpengaruh terhadap kepatuhan sebesar $18,9 \%$, sedangkan sisanya $(100 \%-18,9 \%=81,1 \%)$ dipengaruhi oleh variabel lain yang tidak termasuk dalam penelitian ini.

\section{Saran}

Berdasarkan kesimpulan yang di peroleh dalam penelitian ini, maka penulis mengajukan saran sebagai berikut:

\section{Bagi KPP Batam Selatan}

a. Agar KPP Pratama memberikan sosialisasi rutin tentang manfaat penggunaan e-filing dalam pelaporan pajak.

b. KPP Pratama Batam Selatan harus memperhatikan factor - factor yang memperngaruhi wajib pajak tidak melaporkan pajaknya dan segera mencari solusi untuk hal itu. Dalam penelitian ini peneliti mengamati bahwa wajib pajak tidak perduli akan pajak, banyak wajib pajak yang sama sekali tidak pernah mendengar system pelaporan pajak menggunakan e-filing. Dan bahkan tidak pernah lapor pajak, hal ini terjadi karna perusahaan tempatnya bekerja langsung membayar dan melaporkan pajak karyawannya ke kantor pajak.

c. KPP Pratama Batam Selatan juga harus memperhatikan bahwa Batam adalah kota industry dimana banyak siswa yang baru lulus datang merantau ke kota ini menjadi karyawan dan wajib pajak di kota ini. Sosialisasi tentang pemahaman pajak dan layanan yang ditawarkan kantor pajak sangat penting bagi mereka agar mereka tau manfaat pajak dan penggunaan system yang telah diterapkan kantor pajak. 
2. Bagi Peneliti Selanjutnya

a. Diharapkan bagi peneliti selanjutnya, penelitian ini lebih dikembangkan lagi atau menambah jumlah variabel lain yang tidak diteliti dalam penelitian ini.

\section{REFERENSI}

Akbar, Rofiq Faudi, (2015), Analisis Persepsi Pelajar Tingkat Menegah Pada Sekolah Tinggi Agama Islam Negri Kudus.

Arikunto, Suharsimi. (2010). Prosedur Penelitian Suatu Pendekatan Praktek. Jakarta: RinekaCipta

Dewi, A. K., Suhadak dan Dewi, F. A., (2016). Pengaruh Persepsi Dan Perilaku Wajib Pajak Atas Penerapan E-Filing Terhadap Kepatuhan Wajib Pajak Pribadi Yang Terdaftar Di KPP Batam Selatan. Jurnal Perpajakan (JEJAK), Vol. 10, No. 1. 2016.

Febrianti, Tri Yulia, (2014). Pengaruh Pengetahuan Perpajakan dan Kesadaran Pajak Terhadap Kepatuha Wajib Pajak Orang Pribadi

Gunawan.Teddy, Eny. Suprapti, Eris. T.K, (2014). Persepsi wajib pajak mengenai E-Filing dan pengaruhnya terhadap tingkat kepatuhan wajib pajak orang pribadi dalam melaporkan pajak, Jurnal Reviu Akuntansi dan Keuangan ISSN: 2088-0685. Vol.4 No. 2, Oktober 2014,, Pp 615-622

Hamdi, Asep Saepul dan E. Bahruddin.(2014). Metode Penelitian Kuantitatif Aplikasi Dalam Pendidikan. Yogyakarta: Deepublish

Hidayat, danNugroho. (2010). Studi Empiris Theory Of Planned Behavior dan Pengaruh Kewajiban Moral Pada Perilaku Ketidakpatuhan Pajak Wajib Pajak Orang Pribadi',. Jurnal Akuntansi dan Keuangan, Vol. 12, no. 2, November 2010: 82-93.

Kementrian Keuangan.(2018). Surat Pemberitahuan Tahunan (E-SPT) Dalam:http://www.integrasiedukasi.org/seri-tutorial-e-spt-pengisian-e-spt-pajak-penghasilan-pasal-21/.

Kementrian Keuangan.(2018). Pelaporan Pajak Tahunan Melalui E-Filing. Dalam :http://www.pajak.go.id/content/article/e-filing-cara-mudah-cepat-dan-aman-lapor-pajak

Kolompoy, Calvin. VentjeIlat, dan Harijanto S. (2015). Pengaruh Perilaku Individu Wajib Pajak Orang Pribadi Terhadap Penggunaan E-Filing.

Nurhasanah, Firmansyah, dan Ima N. (2015). Pengaruh Persepsi Wajib Pajak Orang Pribadi Terhadap Penggunaan Electronic Filling (e-filling) di KPP Pratama Palembang Ilir Bara. Jurnal Akuntanika, No. 1, Vol. 1, Januari - Juni 2015

Nurlaela, Lina. (2017). Pengaruh Penerapan E-Filing Terhadap Kepatuhan Wajib Pajak Di KPP Pratama Garut.

Notoatmodjo, Soekidjo. (2003). Pendidikan Dan Perilaku Kesehatan.Rineka Cipta. Jakarta. 
Manurung, Adler H. danLutfi T. Rizky. 2009. Successful Financia Planner:A Complete Guide, Jakarta: Grasindo.

Rahayu, Siti Kurnia \& Ely Suhayati. 2010. Perpajakan Indonesia.Yogyakarta :GrahaPustaka

Suherlan Herlan \& Yono Budhiono. (2013). Psikologi Pelayanan. Bandung: Penerbit Media Perubahan.

Suherman, Maman. Medina .A, danRina M. (2015). Pengaruh Penerapan E-Filing Terhadap Kepatuhan Wajib Pajak dalam Penyampaian Surat Pemberitahuan (SPT) Tahunan Pada Kantor Pelayanan Pajak Pratama Kota Tasikmalaya. Vol. 15 No. 1 April 2015

Sugiyono.(2015). Metode Penelitian Kuantitatif Kualitatifdan R\&D.Bandung :Alfabeta

Sarwono, S. W. Psikologi remaja. Edisirevisi 8.Jakarta : Raja GrafindoPustaka,2004.

Ulyani, Thropy Atika. (2017). Pengaruh Persepsi Wajib Pajak Atas Penerapan E-System dan Account Representative terhadap kepatuhan (Studi Pada Kantor Pelayanan Pajak Pratama Kendari). JurnalAkuntansi (JAk).

Wibisono, Lisa Tamara dan Agus Arianto Toly. (2014). Analisis Faktor - Faktor Yang Mempengaruhi Minat Wajib Pajak Dalam Pengunaan E-Filinf Di Surabaya. 